\title{
Codeposition of deuterium with ITER materials
}

\author{
R.P. Doerner ${ }^{1}$, M.J. Baldwin ${ }^{1}$, G. De Temmerman ${ }^{2}$, J. Hanna ${ }^{1}$, D. Nishijima ${ }^{1}$, \\ J. Roth ${ }^{3}$, K. Schmid ${ }^{3}$, G.R. Tynan ${ }^{1}$ and K. Umstadter ${ }^{1}$ \\ ${ }^{1}$ University of California at San Diego, La Jolla, CA. 92093-0417 USA \\ 2 EURATOM/UKAEA Fusion Association, Abingdon, UK \\ ${ }^{3}$ Max-Plank-Institut für Plasmaphysik, Garching, Germany \\ e-mail: rdoerner@ucsd.edu
}

\begin{abstract}
:
The levels of retention in codeposited layers of each of the three ITER materials (C, Be and W) are compared. Scaling laws, based on the conditions during the codeposition process (surface temperature, incident particle energy and ratio of the depositing fluxes), are presented to allow prediction of expected retention under ITER conditions. Retention in carbon codeposits scales inversely with incident particle energy, whereas in the metallic codeposits the retention level scales proportional to increasing particle energy. The differing scaling of retention with incident particle energy provides insight into which material may impact the global retention in ITER depending on where it may form codeposits. In addition to the amount of retention, the release behavior of tritium from codeposits will influence the tritium accumulation rate within ITER. The thermal release behavior of $\mathrm{T}$ (or $\mathrm{D}$ ) from codeposits can be used to evaluate the effectiveness of baking at different temperatures as a means of tritium removal. Finally, the desorption kinetics from Be and $\mathrm{W}$ codeposits are contrasted. In the case of $\mathrm{W}$ codeposits, the duration of the baking cycle is important in determining the removal efficiency, whereas with Be codeposited layers, the maximum achievable bake temperature plays the leading role in determining removal efficiency.
\end{abstract}

\section{Introduction}

The issue of tritium accumulation within the ITER vacuum vessel is one of the highest priority challenges facing the ITER team as it moves forward with finalizing its design and interfacing with the licensing authorities. Once a certain amount of tritium is retained within the ITER vacuum vessel (likely to be $700 \mathrm{~g}$ ) [1], it may be necessary to halt operations until removal of the stored tritium can be accomplished. Tritium retention occurs in two ways, through direct implantation into plasma-facing surfaces and through codeposition with materials that are eroded from these plasma-facing surfaces. Of these two processes, codeposition is expected to dominate. In this presentation, we will compare the 
tritium retention properties of codeposits formed of each of the three main materials used as plasma-facing materials in the present ITER design: beryllium, tungsten and carbon.

In order to predict the tritium accumulation rate in ITER it is necessary to model the interaction of the edge and scrape-off layer plasma with different areas of the ITER plasmafacing components. In addition, thermal conduction models need to be used to predict the surface temperature of each area of the plasma-facing components in the ITER design. Such modeling efforts are beyond the scope of this presentation, but have been presented by other authors in the literature [1-3]. This paper presents the basis for the prediction of the amount of tritium retained in codepositing materials that are generated by the differing materials and modeling approaches.

In addition to the amount of retention, the release behavior of tritium from codeposits will influence the tritium accumulation rate within ITER. The thermal release behavior of $\mathrm{T}$ (or $\mathrm{D}$ ) from codeposits can be used to evaluate the effectiveness of baking at different temperatures as a means of tritium removal. The thermally activated release behavior of differing codeposits is presented to estimate the effectiveness of varying the bake out temperature of the ITER vessel.

\section{Retention in Beryllium Codeposits}

The present ITER design uses beryllium as the plasma-facing material on the large area of the first wall. Even though comparatively little plasma is expected to reach the first wall surfaces, a significant amount of beryllium is expected to be sputtered from this area and to be transported to other areas of the first wall and throughout device. For this reason the deuterium retention in beryllium codeposits has been the subject of several studies [4, 5]. Unfortunately, these studies resulted in a large scatter of the expected value for the $\mathrm{D} / \mathrm{Be}$ ratio present in the various Be codeposits.

A systematic study of beryllium codeposits [6] has recently been performed to understand the reasons for the large scatter of $\mathrm{D} / \mathrm{Be}$ values found in the literature. This study developed a scaling law with which to predict the level of D/Be found in Be codeposits based on three experimental variables (the surface temperature of the codeposit, $T_{c}$, the deposition rate of beryllium, $\mathrm{r}_{\text {dep }}$, and the incident energy of deuterium interacting with the Be codeposit, $\mathrm{E}_{\mathrm{n}}$ ) encountered during the formation of Be codeposits [6]. When this scaling is applied to the $\mathrm{D} / \mathrm{Be}$ database, the large scatter observed in the literature is significantly reduced. The data that was contained in the original scaling study has recently been reevaluated in terms of the ratio of the flux of deuterium to the flux of beryllium arriving at 
the collector surface [7]. The revised scaling was developed to allow for easier extrapolation to codeposition conditions expected in ITER, where the deposition rate of beryllium in PISCES-B is much smaller than that expected in ITER, but where the flux ratio of deuterium to beryllium arriving at the collector is similar to that expected in ITER. The revised retention scaling was found to be,

$$
\left.\mathrm{D} / \mathrm{Be}=\left(5.82 \times 10^{-5}\right)^{*} \mathrm{E}_{\mathrm{n}}{ }^{1.17} *\left(\Gamma_{\mathrm{D}} / \Gamma_{\mathrm{Be}}\right)^{-0.21} * \exp ^{(2273 / \mathrm{T}} \mathrm{C}\right)
$$

This scaling is strictly only valid over the ranges of the parameters studied; $293 \mathrm{~K}<\mathrm{T}_{\mathrm{C}}<$ $600 \mathrm{~K}, 10<\left(\Gamma_{\mathrm{D}} / \Gamma_{\mathrm{Be}}\right)<2000$, and $15<\mathrm{E}_{\mathrm{n}}<60 \mathrm{eV}$. Some care must, therefore, be exercised while applying this prediction to all areas of the ITER vessel, but it is possible to obtain some insight into trends that should be expected for Be codeposition in different areas of the ITER vessel.

\section{Retention in Tungsten Codeposits}

Although the amount of tritium retention expected in tungsten codeposits is thought to be small, it was necessary to verify this assumption to reduce the risk of any unforeseen surprises after the construction of ITER. For this reason, a similar study of deuterium retention in tungsten codeposits has recently been completed [8]. As in the study of Be codeposits, the surface temperature, the ratio ofr the arriving flux of deuterium atoms to the depositing atom flux and incident particle energy are seen to correlate to the D/W ratio present in the $\mathrm{W}$ codeposits. In the case of $\mathrm{W}$ codeposition, the scaling equation was found to be,

$$
\left.\mathrm{D} / \mathrm{W}=\left(5.13 \times 10^{-8}\right) * \mathrm{E}_{\mathrm{n}}^{1.85} *\left(\Gamma_{\mathrm{D}} / \Gamma_{\mathrm{W}}\right)^{0.4} * \exp ^{(736 / \mathrm{T}} \mathrm{C}\right)
$$

where the range of the variables investigated was; $293 \mathrm{~K}<\mathrm{T}_{\mathrm{c}}<600 \mathrm{~K}, 5<\left(\Gamma_{\mathrm{D}} / \Gamma_{\mathrm{W}}\right)<500$, and $60<\mathrm{E}_{\mathrm{n}}<280 \mathrm{eV}$.

For typical values of codeposition parameters similar between the two studies, the tungsten codeposition level, D/W, is approximately two to three orders of magnitude less than the beryllium codeposition level, D/Be. This retention result, coupled with the lower tungsten impurity generation rate (i.e. sputtering yield) expected in ITER, effectively eliminates tritium accumulation concerns for tungsten codeposits. 


\section{Retention in Carbon Codeposits}

In the case of carbon codeposits, it is not possible to examine such codeposits in PISCES-B because the deposition rate is much smaller than the erosion rate of a carbon codeposit due to the background atomic deuterium flux. This is because of the large yield of carbon chemical erosion that does not exist for either beryllium or tungsten codeposits.

It is therefore necessary to rely on published results to try to extract a similar scaling law for carbon codeposition. Figure 1a shows the D/C ratio obtained during two systematic investigations of carbon codeposition in laboratory-based experiments [9, 10]. Also shown in the figure are measurements of $\mathrm{D} / \mathrm{C}$ values found during post-mortem analysis of codeposits produced over long run campaigns in several confinement devices [11, 12, 13]. The agreement between laboratory results and confinement machines adds confidence in any scaling developed based on the results of the systematic laboratory investigations.

The work performed by Von Keudell [8] revealed different retention behavior in codeposits formed below $473 \mathrm{~K}$ (saturated D/C levels below $473 \mathrm{~K}$ ), as compared to those formed above $473 \mathrm{~K}$ (decreasing $\mathrm{D} / \mathrm{C}$ level with increasing $\mathrm{T}_{\mathrm{c}}$ ). In the case of ITER codeposits formed below $473 \mathrm{~K}$ are not particularly relevant (since the minimum surface temperature within the vessel is expected to be close to $473 \mathrm{~K}$ ) and so a saturated $\mathrm{D} / \mathrm{C}$ value of between $0.4-1$ can be assumed. For the scaling presented here a saturated D/C level of that obtained at $473 \mathrm{~K}$ is used. The trend of decreasing retention with increasing temperature is similar to that observed in both the Be and $\mathrm{W}$ codeposits. The effect of incident particle energy was investigated Jacob [14] and the $\mathrm{D} / \mathrm{C}$ value is found to scale as $\mathrm{E}_{\mathrm{n}}{ }^{-0.43}$. The dependence of retention on incident particle energy is opposite to that observed in the metallic codeposits described in sections 2 and 3.

No information was found in the literature on the dependence of the $\mathrm{D} / \mathrm{C}$ ratio with variations in the ratio of the arriving flux of atomic deuterium to carbon. The dependence on the ratio of the arriving fluxes is, therefore, not included in the scaling (i.e. D/C is proportional to $\left.\left(\Gamma_{\mathrm{D}} / \Gamma_{\mathrm{C}}\right)^{0}\right)$. By not including a scaling with arrival flux ratio, the assumption is that the carbon layer is saturated with deuterium. In other words, it is assumed that there are always plenty of deuterium atoms incident on the growing carbon layer to saturate the layer, even if the deposition rate of carbon is increased.

The best fit scaling obtained for the $\mathrm{D} / \mathrm{C}$ values in carbon codeposits is found to be,

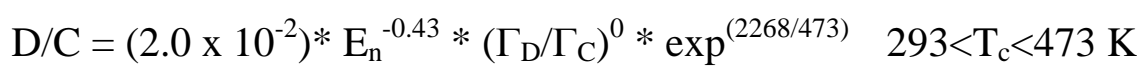




$$
\left.\mathrm{D} / \mathrm{C}=\left(2.0 \times 10^{-2}\right)^{*} \mathrm{E}_{\mathrm{n}}^{-0.43} *\left(\Gamma_{\mathrm{D}} / \Gamma_{\mathrm{C}}\right)^{0} * \exp ^{(2268 / \mathrm{T}} \mathrm{C}\right) \quad 473<\mathrm{T}_{\mathrm{C}}<973 \mathrm{~K}
$$

where the D/C data was obtained for $293 \mathrm{~K}<\mathrm{T}_{\mathrm{c}}<973 \mathrm{~K}$ and $15<\mathrm{E}_{\mathrm{n}}<100 \mathrm{eV}$. Figure $1 \mathrm{~b}$ shows the comparison of this D/C scaling to the laboratory studies of carbon codeposits. The scaling has been applied at two different incident energies; $15 \mathrm{eV}$ to compare to the experimental conditions of Von Keudell [10] and $68 \mathrm{eV}$ similar to the Alimov experiments [9].

\section{Release of Tritium from Codeposited Material}

Perhaps more important than the amount of tritium retained in different codeposited materials, is the ease at which the retained tritium can be liberated from the codeposits. There has been extensive work done on removing $\mathrm{T}$ from $\mathrm{C}$ codeposits by means of troublesome techniques such as oxidation [15]. However, it would be preferable, if possible, to remove the $\mathrm{T}$ from codeposits during simpler thermal annealing (i.e. baking). The release behavior of $\mathrm{T}$ from $\mathrm{C}$ codeposits during annealing has been documented [16].

The conditions (deposition rate, temperature, incident energy) present during the codeposition process not only determine the absolute quantity of fuel species retained within the codeposit, but also impact the structure of the codeposit. Codeposits formed at higher surface temperature, tend to form denser (less porous) layers, while increases in the background neutral pressure during codeposition tends to favor the formation of more porous codeposited layers [17]. The behavior of the codeposits agrees qualitatively with the 'Zone Model' [18] of film growth proposed by Thornton in the early days of magnetron sputter deposition. The resultant structure of the codeposited layer can impact the release behavior of deuterium during thermal annealing of the layers [19].

For a given incident particle energy, more porous codeposited layers tend to retain more fuel atoms than denser codeposits. However, codeposits that exhibit porosity also tend to thermally release the incorporated deuterium at lower temperature. The deuterium release behavior of two beryllium codeposits formed at the same surface temperature, but exhibiting different levels of porosity (due to changes in the background neutral density) are compared in figure 2a. In this case argon has been added to deuterium plasma in PISCES-B to achieve the formation of a denser codeposited layer. Also indicated in figure 2a is the presently envisioned bake out temperature of the ITER vessel ( $\sim 13 \mathrm{~K})$. It may be possible to bake the divertor only to a higher temperature (after the coolant has been drained from the divertor system) of $\sim 648 \mathrm{~K}$, which is also indicated in the figure. [It should be noted that 
a divertor baking system capable of achieving $573 \mathrm{~K}$ has recently been included into the baseline ITER design]. The value of the maximum achievable bake temperature is crucial for ITER because the release behavior from beryllium codeposits does not appear to be a diffusion dominated process. Figure $2 b$, normalizes and replots the data from figure $2 a$ to show the amount of deuterium remaining in the codeposited Be layer as a function of the bake out temperature.

The metallic codeposits of $\mathrm{W}$ and Be have quite different desorption kinetics. To exhibit this, two codeposited layers formed at close to room temperature were outgassed using a stepwise baking scenario. In both cases, the deuterium-outgassing rate was monitored using a QMS while the temperature of the codeposit was varied. The W codeposit was subjected to a heating ramp rate of $18 \mathrm{~K} / \mathrm{min}$ up to $600 \mathrm{~K}$ and then maintained at $600 \mathrm{~K}$ for $2600 \mathrm{sec}$. After this plateau, the heating ramp was applied again until the codeposit temperature reached $1100 \mathrm{~K}$. In the case of the $\mathrm{W}$ codeposit, once the temperature reaches its plateau, the desorption rate decreases exponentially (with a time constant of approximately $300 \mathrm{sec}$.) to almost zero at 4000s (figure 3a). When the temperature is ramped up again, the desorption rate stays small, only increasing slightly at around $1000 \mathrm{~K}$. This indicates that almost all of the retained deuterium has been desorbed slowly during the temperature plateau.

This behavior is radically different to what is observed for a beryllium co-deposited layer. In this case, the temperature during the bake out was increased up to $520 \mathrm{~K}$ using the same heating rate as for the tungsten codeposit, and then maintained at this value for 1 hour. In this case, the desorption rate falls down to zero (figure $3 b$ ) very quickly after the beginning of the plateau and remains below the detection limit for the entire plateau. When the temperature ramp is restarted to raise the codeposit temperature to $1273 \mathrm{~K}$ (similarly to the case with the $\mathrm{W}$ codeposit), the desorption rate increases back to a level close to the value at which it ceases when the temperature ramp was stopped. It is also worth noting that if one removes the plateau phase and adds the 2 spectra obtained before and after the plateau, one obtains a similar spectrum to that observed with a continuous heating phase of a similarly formed Be codeposit, as shown in figure 4.

These observations indicate that the desorption kinetics are different for beryllium and tungsten codeposited layers. While desorption from tungsten layers seems to be limited by the diffusion of deuterium through the layer, desorption from beryllium layers does not seem governed by diffusion. Beryllium deuteride $\left(\mathrm{BeD}_{2}\right)$ has been observed in $\mathrm{Be}$ codeposits [20] and this molecule may affect the deuterium release kinetics from the 
codeposit. Recent results on the release of deuterium from carbon codeposits [21] show a similar behavior to those shown here for beryllium codeposits. Again this is most likely related to the hydrogen bonding that exists within the carbon codeposit. This release behavior has implications for the possible tritium removal from such layers by a bake out of the vacuum vessel. Indeed, in the case of beryllium (and carbon) the maximum achievable temperature is the critical parameter, while the duration of the bake out is more important in the case of tungsten.

\section{Conclusion}

Scaling laws for tritium retention in codeposits of each of the three likely ITER materials (C, Be and W) have been developed based on systematic laboratory studies. In the case of carbon codeposits, the scaling law tends to reproduce post-mortem analysis of codeposits removed from several tokamaks. In the case of Be codeposits, there is no database from operating confinement devices to compare with, but the scaling law has been applied to results from several laboratory devices and is found to reproduce the measured retention. In the case of $\mathrm{W}$ codeposits, the database for comparison is even smaller, but since the measured retention levels are so low, retention in $\mathrm{W}$ codeposits is not considered to be a significant issue.

Comparing the $\mathrm{W}, \mathrm{C}$ and Be scaling laws can provide insight into the most worrisome locations of each for codeposit formation. The amount of tritium retained in codeposits is fairly insensitive to the ratio of fluxes of the arriving species, however both the incident particle energy (figure 5a) and temperature of the codepositing surface (figure 5b) have a strong impact on the level of retention. In all cases, the higher the surface temperature, the lower the retention level, so this can be used to argue for increasing the surface temperature throughout the ITER vessel. While both Be and C codeposits appear to have similar scaling with increasing temperature, the $\mathrm{T}$ content in $\mathrm{C}$ codeposits is constant until above $473 \mathrm{~K}$. Above this temperature the trend in retention vs. temperature between $\mathrm{Be}$ and $\mathrm{C}$ is identical (see figure $5 \mathrm{~b}$ ). The striking difference between the scaling laws of $\mathrm{Be}$ and $\mathrm{C}$ is their incident particle energy relationships. In the case of $\mathrm{C}$, the retention increases as the energy of the incident particle decreases. Soft, polymer-like carbon films form during low-energy particle bombardment and these 'soft' films tends to have high hydrogen content. As the incident particle energy increases the carbon layer density tends to increase resulting in so-called 'hard' films, with lower hydrogen content. 
Be codeposits also tend to denser structures as the incident particle energy increases, but the retention property of the denser codeposit behaves oppositely. As the incident particle energy increases, the retention level within the codeposit also increases. The increased retention may result from the decrease in porosity of the film that results in fewer pathways for implanted tritium to return to a surface where it can recombine and eventually, through the open porosity, find its way back out of the codeposited layer.

The interesting comparison between $\mathrm{C}$ and Be codeposits stems from this difference in retention with incident particle energy. Codeposits forming in the divertor region are likely to be subjected to lower energy particle bombardment. If $\mathrm{C}$ codeposits dominate in the divertor, they will likely contain a significant $\mathrm{D} / \mathrm{C}$ value. Be codeposition in the divertor region; however, will likely contain lower D/Be levels. On the other hand, if Be codeposits form in the first wall region, where CX particle energies are likely to be higher [22], there could be significant $\mathrm{D} / \mathrm{Be}$ values found within these codeposits. As the incident particle energy increases the level of $\mathrm{D} / \mathrm{Be}$ in Be codeposits can exceed the $\mathrm{D} / \mathrm{C}$ level expected from similar $\mathrm{C}$ codeposits, as shown in figure $5 \mathrm{a}$. The variation of the temperature dependence on retention in each type of codeposit is shown in figure 5b. Also apparent from figures $5 \mathrm{a}$ and $\mathrm{b}$, the retention level expected in $\mathrm{W}$ codeposits is expected to be small under almost all conditions.

The desorption kinetics of deuterium from $\mathrm{W}$ and Be codeposits have been investigated. The desorption from $\mathrm{W}$ codeposits appears to be diffusion limited release process, where a longer duration of the heating cycle can be used to achieve an increase in the amount of deuterium released. This is not true for Be codeposited layers. The desorption from Be codeposits depends on the maximum temperature achieved during the baking cycle, rather than on the duration of the heating cycle. The Be desorption kinetics may provide hope that flash heating of the codeposited layers (for example, during a radiated termination [23] of an ITER discharge) may be sufficient to remove a significant fraction of the fuel species from the codeposited layer.

\section{Acknowledgements}

This work was supported by both the USDOE and EFDA as part of an ongoing USEU collaboration on mixed materials. This support, along with the support of many scientists both in the EU and within the US, is appreciated. 
Codeposition of deuterium with ITER materials

\section{References}

[1] J. Roth et al., Plasma Phys. Control. Fusion 50 (2008) 103001.

[2] J. Roth et al., 22 ${ }^{\text {nd }}$ IAEA Fusion Energy Conference, Geneva (2008).

[3] J. N. Brooks, J. P. Allain, R. P Doerner, A. Hassanein, R. Nygren, T. D. Rognlien and

D. Whyte, $22^{\text {nd }}$ IAEA Fusion Energy Conference, Geneva, submitted to Nucl. Fus. (2008).

[4] R. A. Causey and D. S. Walsh, J. Nucl. Mater. 254 (1998) 84.

[5] M. J. Baldwin, K. Schmid, R. P. Doerner, A. Wilner, R. Seraydarian and Ch. Linsmeier, J. Nucl. Mater. 337-339(2005)590.

[6] G. De Temmerman, M. J. Baldwin, R. P. Doerner, D. Nishijima and K. Schmid, Nucl. Fusion 48 (2008) 075008.

[7] G. De Temmerman and R. P. Doerner, submitted to Nucl. Fusion (2008).

[8] G. De Temmerman and R. P. Doerner, submitted to J. Nucl. Mater. (2008).

[9] V. Kh. Alimov, Phys. Scripta T108 (2004) 46.

[10] A. von Keudell, W. Moller and R. Hytry, Appl. Phys. Lett. 62 (1993) 937.

[11] A. T. Peacock et al., Fusion Engr. Des. 49-50 (2000) 745.

[12] W. R. Wampler, B. L. Doyle, S. R. Lee, A. E. Ponyau, B. E. Mills, R. A. Causey, D. Buchenauer, H. F. Dylla, M.A. Ulrickson and P. H. LaMarche, J. Vac. Sci. Technol. A 6 (1988) 2111.

[13] Y. Hirohata et al., J. Nucl. Mater. 367-370 (2007) 1260.

[14] W. Jacob, Thin Solid Films 326 (1998) 1.

[15] A. A. Haasz, C. K. Tsui, J. W. Davis and R. Ochoukov, Phys. Scr. T128 (2007) 55.

[16] R. A. Causey, W. R. Wampler and D. Walsh, J. Nucl. Mater. 176\&177 (1990) 987.

[17] G. De Temmerman, M. J. Baldwin, R. P. Doerner, D. Nishijima, R. Seraydarian, K.

Schmid, F. Kost, Ch. Linsmeier and L. Marot, J. Appl. Phys. 102 (2007) 083302.

[18] J. Thornton, J. Vac. Sci., 11(1974)666.

[19] G. De Temmerman et al., accepted for publication in J. Nucl. Mater. from PSI-18, Toledo Spain (2008).

[20] R. P. Doerner et al., accepted for publication in J. Nucl. Mater. from PSI-18, Toledo Spain (2008).

[21] F. Genoese et al., "Hydrogen and hydrocarbon release during thermal decomposition of hydrocarbon layers under vacuum”, presented at PSI-18, Toledo Spain (2008).

[22] R. Behrisch et al., J. Nucl. Mater. 313-316 (2003) 388.

[23] D. G. Whyte et al., Phys. Rev. Lett. 89 (2002) 055001. 


\section{Codeposition of deuterium with ITER materials}

Figure captions

Figure 1 - a) Comparison of systematic laboratory studies of D/C level in carbon codeposits to D/C level found during post-mortem analysis of codeposits found after long periods of tokamak operation, b) Comparison of D/C laboratory results with deuterium retention scaling presented in Eq. 3a\&b.

Figure 2 -a) Deuterium release characteristics from two beryllium codeposits created at $373 \mathrm{~K}$, but containing different levels of porosity due to the addition of Ar to the plasma. b) Normalization of data from a) indicating the amount D released from each codeposit as the temperature is increased. Also indicated in the figures are the present ITER main vessel bake temperature of $513 \mathrm{~K}$, and the possible divertor bake temperature (after coolant drain) of $648 \mathrm{~K}$.

Figure 3 - Desorption behavior of (a) a tungsten co-deposited layer formed by magnetron sputtering at $293 \mathrm{~K}$ and of (b) a beryllium co-deposited layer prepared in PISCES-B at 373 K.

Figure 4 - A comparison of the thermal release of deuterium from two identical beryllium codeposits. The thermal desorption of each codeposit was identical except that one codeposit was held at $\mathrm{x} \mathrm{K}$ for one hour during the bakeout (see Fig. 3b). By removing this flattop time period from the plots, one obtains essentially the same thermal desorption profile.

Figure 5 - Expected retention levels in tungsten, beryllium and carbon codeposits; a) incident particle energy variation of equations 2, 3a and 4 evaluated at $473 \mathrm{~K}$ and flux arrival ratio of 100 deuterium atoms per depositing species, b) temperature variation of equations 2, 3a\&b and 4 evaluated at $20 \mathrm{eV}$ incident particle energy and flux arrival ratio of 100 deuterium atoms per depositing species. 
a)

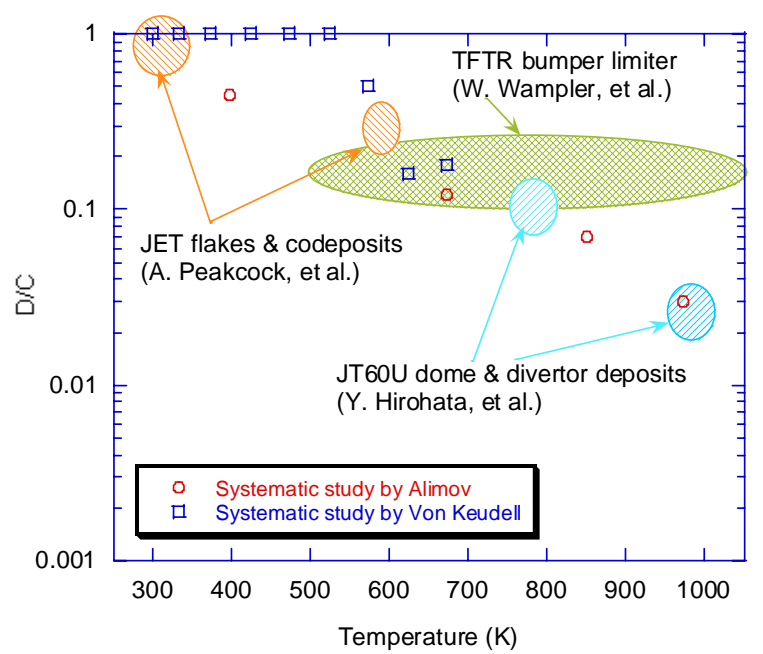

b)

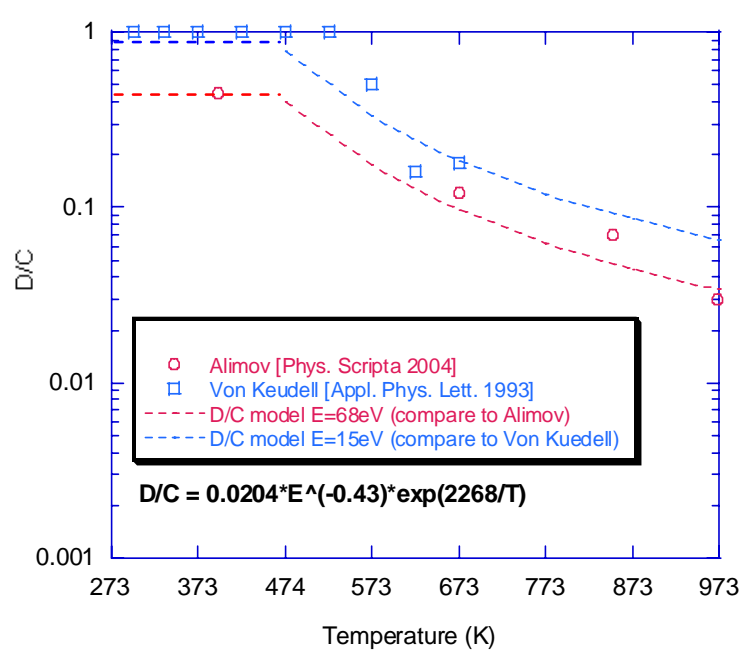

Figure $1-a)$ Comparison of systematic laboratory studies of D/C level in carbon codeposits to D/C level found during post-mortem analysis of codeposits found after long periods of tokamak operation, b) Comparison of D/C laboratory results with deuterium retention scaling presented in Eq. 3a\&b. 

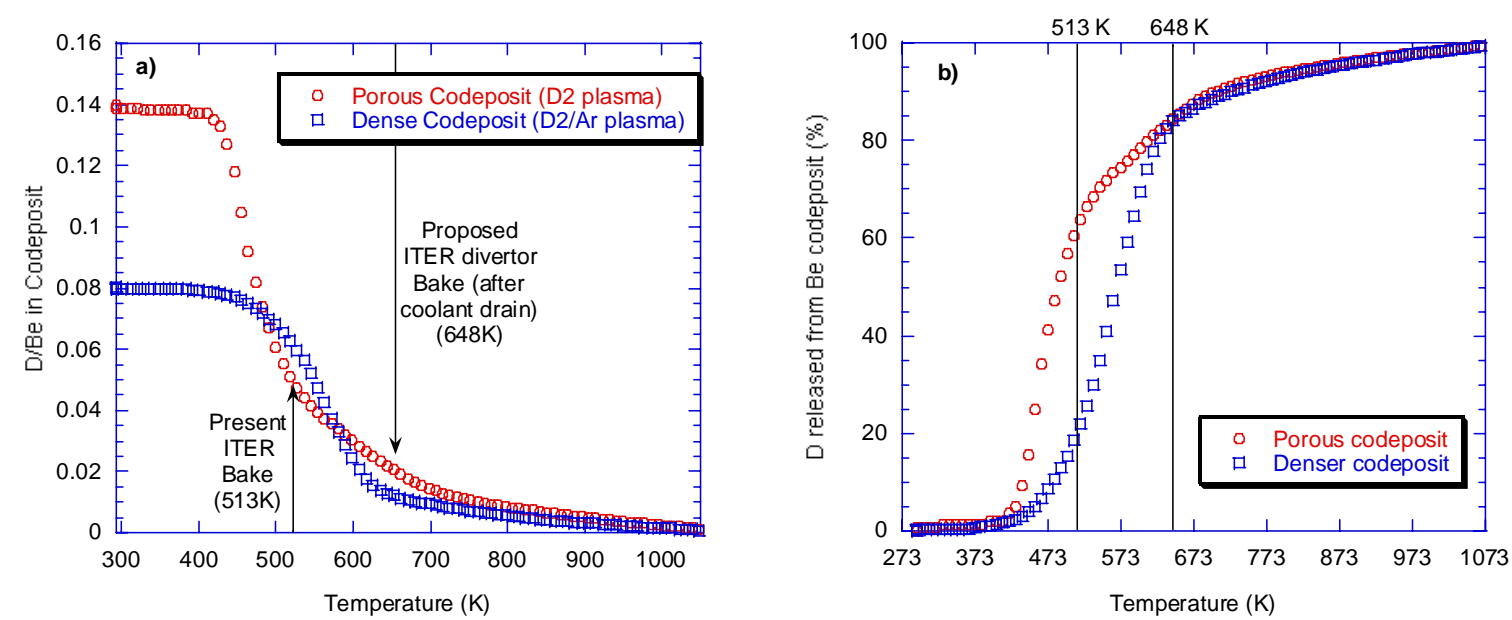

Figure 2 - a) Deuterium release characteristics from two beryllium codeposits created at $373 \mathrm{~K}$, but containing different levels of porosity due to the addition of Ar to the plasma. b) Normalization of data from a) indicating the amount $\mathrm{D}$ released from each codeposit as the temperature is increased. Also indicated in the figures are the present ITER main vessel bake temperature of $513 \mathrm{~K}$, and the possible divertor bake temperature (after coolant drain) of $648 \mathrm{~K}$. 

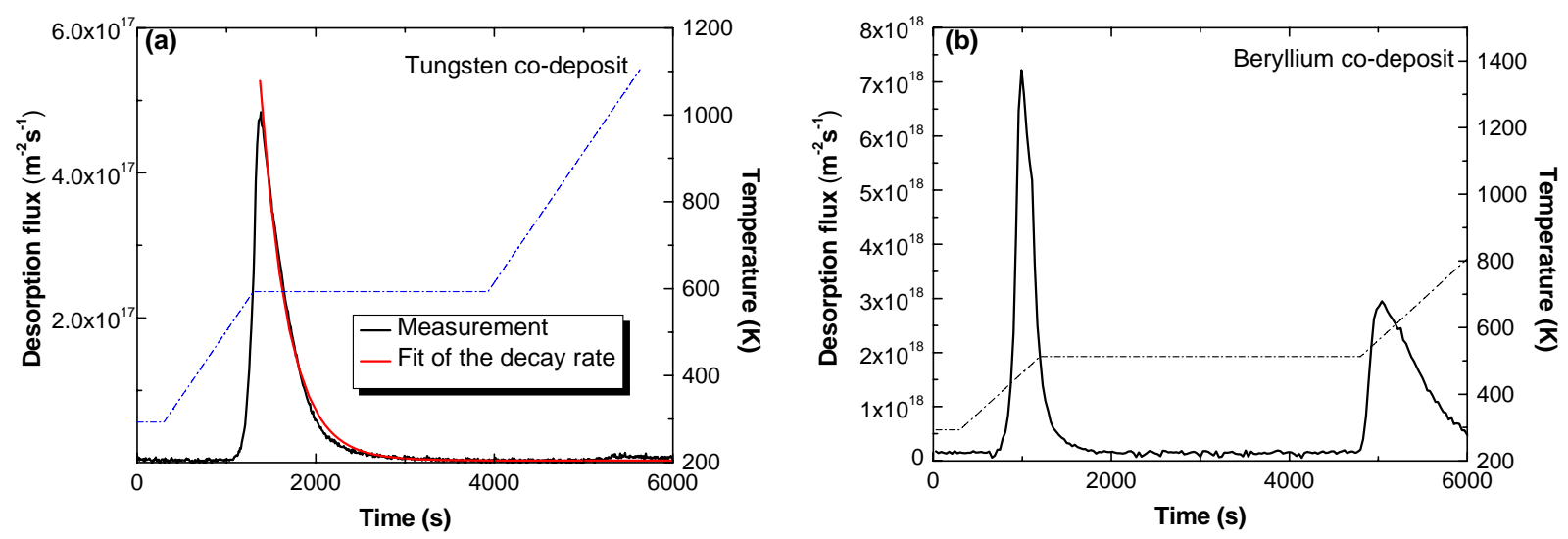

Figure 3 - Desorption behavior of (a) a tungsten co-deposited layer formed by magnetron sputtering at $293 \mathrm{~K}$ and of (b) a beryllium co-deposited layer prepared in PISCES-B at 373 K. 


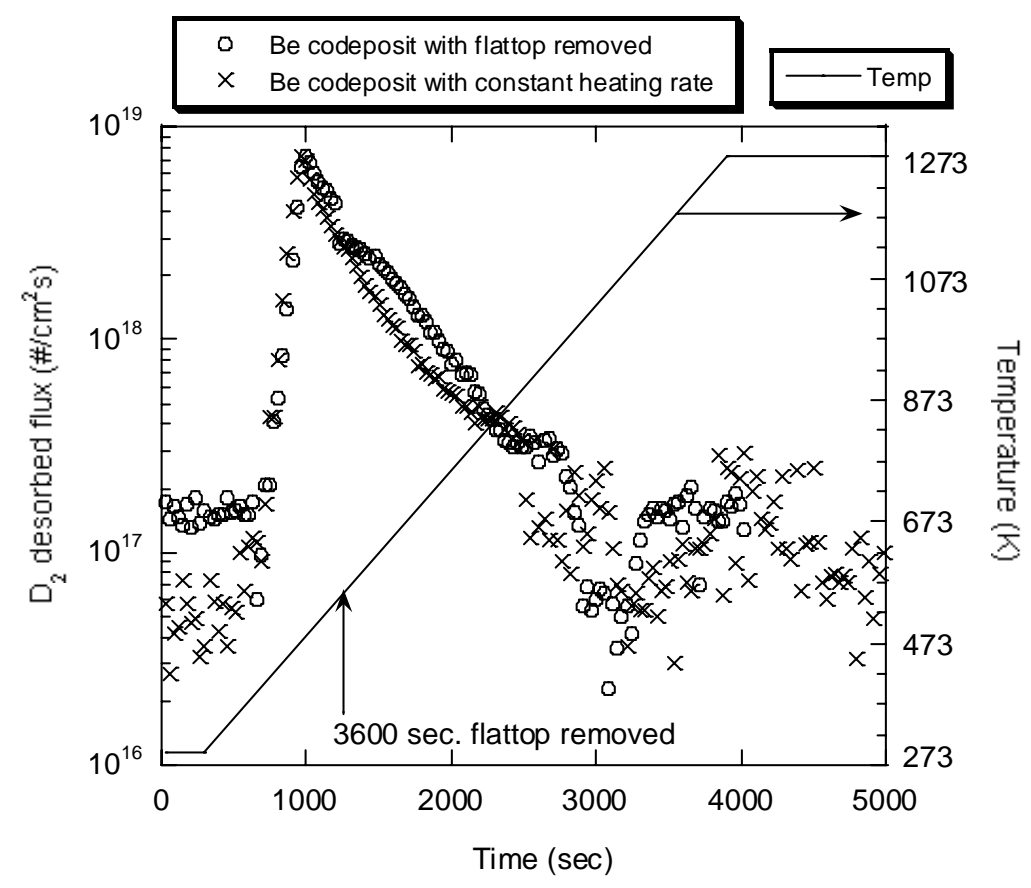

Figure 4 - A comparison of the thermal release of deuterium from two identical beryllium codeposits. The thermal desorption of each codeposit was identical except that one codeposit was held at $\mathrm{x} \mathrm{K}$ for one hour during the bakeout (see Fig. 3b). By removing this flattop time period from the plots, one obtains essentially the same thermal desorption profile. 

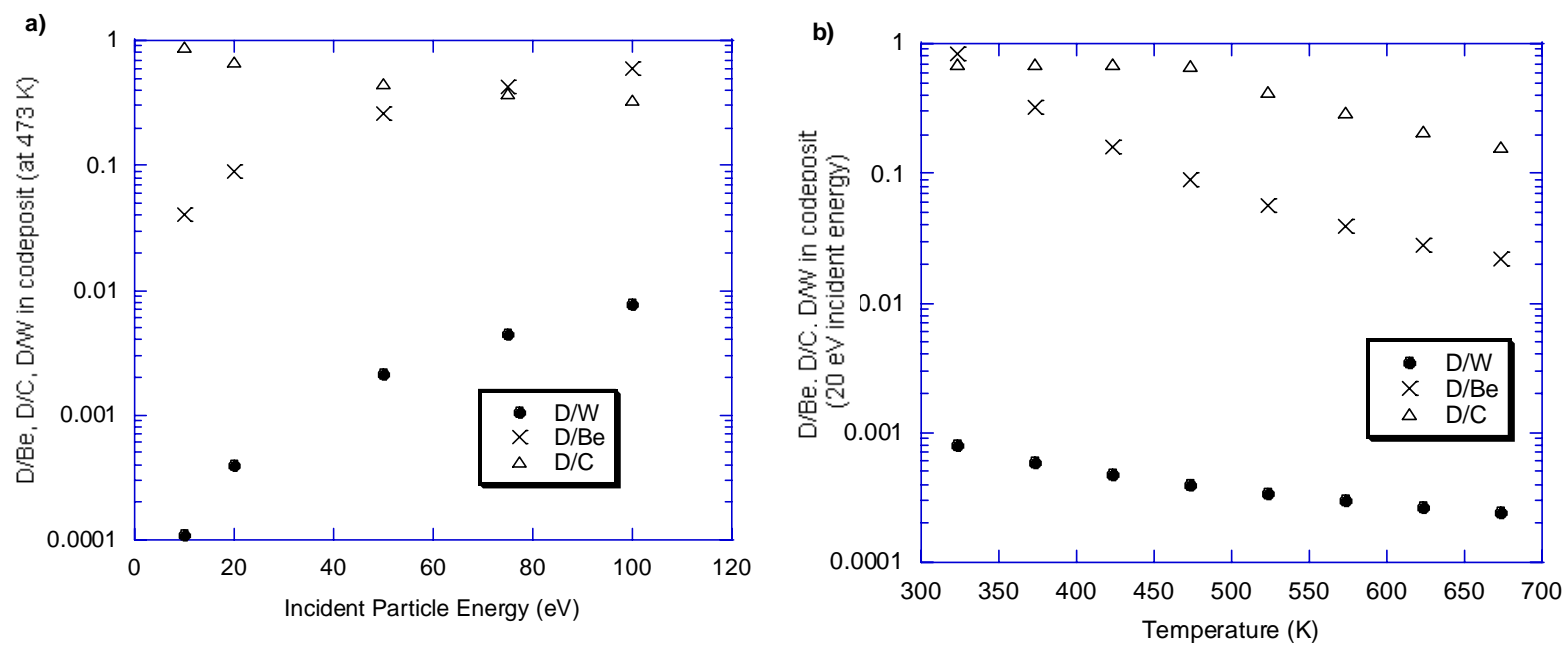

Figure 5 - Expected retention levels in tungsten, beryllium and carbon codeposits; a) incident particle energy variation of equations 2, 3a and 4 evaluated at $473 \mathrm{~K}$ and flux arrival ratio of 100 deuterium atoms per depositing species, b) temperature variation of equations 2, 3a\&b and 4 evaluated at $20 \mathrm{eV}$ incident particle energy and flux arrival ratio of 100 deuterium atoms per depositing species. 